\title{
Oestrogen Alpha-Receptor Variant and Two-Year Memory Decline in Midlife Australian Women
}

\author{
Chad A. Bousman ${ }^{a}$ Cassandra Szoeke $^{a, b}$ Karren Chen ${ }^{b}$ Lorraine Dennerstein ${ }^{b}$ \\ Victor W. Henderson ${ }^{c}$ lan P. Everall ${ }^{a}$

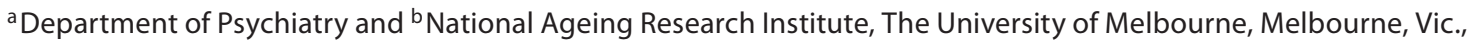 \\ Australia; ' Departments of Health Research and Policy (Epidemiology) and Neurology and Neurological Sciences, \\ Stanford University, Stanford, Calif., USA
}

Key Words

Memory $\cdot$ Genetics $\cdot$ ESR1 $\cdot$ Women

\begin{abstract}
Objective: To prospectively examine the influence of the oestrogen- $\alpha$ receptor (ESR1) Pvull polymorphism on changes in memory performance over a 2-year period among 80 midlife postmenopausal Australian women. Methods: Healthy women aged 56-67 years were administered a battery of four memory (verbal and non-verbal) tasks at baseline and 2 years later. Results: Carriers of the ESR1 $p$ allele had significantly greater declines in logical memory compared to participants with the PP genotype, independent of demographic characteristics (e.g. age), chronic illness (e.g. hypertension), sleep aid usage, hormone levels, apolipoprotein $E$ e4 status and prospective changes in mood, smoking and alcohol consumption. Conclusion: These findings provide preliminary evidence for larger and longer prospective trials that will be able to determine if the p allele of the ESR1 Pvull polymorphism is a potential biomarker of logical memory decline among aging women.
\end{abstract}

Copyright $\odot 2012$ S. Karger AG, Basel

\section{Introduction}

The number of older ( $>60$ years old) persons worldwide is expected to exceed the number of children for the first time in 2045, an event that occurred in 1998 for more developed regions of the world [1]. As the proportion of the world's older population continues to increase so will the incidence of age-related conditions. Some of the most commonly observed conditions in the aging population are related to cognitive decline [2]. In fact, it has been estimated that up to $60 \%$ of women transitioning through menopause self-report problems with memory [3, 4]. However, identifying individuals at greatest risk for decline in memory has proven difficult [5]. At present, dementia is diagnosed only after development of significant impairment of function, and current treatments are suboptimal in that they can at best delay progress of the illness. Thus, early identification of people at risk of cognitive decline prior to development of progressive disease may eventually provide opportunities for early preventive measures.

One potential avenue for improving identification and early targeted treatment is to uncover genetic markers for

\section{KARGER \\ Fax +4161306 1234 E-Mail karger@karger.ch} www.karger.com
Chad A. Bousman, MPH, PhD

Melbourne Brain Centre, Department of Psychiatry

The University of Melbourne

Melbourne, VIC 3010 (Australia)

Tel. +61 39035 8844, E-Mail cbousman@ unimelb.edu.au 
memory decline. Several studies have suggested apolipoprotein $\mathrm{E}(A P O E)$ variation as a biomarker for cognitive decline in elderly populations, particularly in relation to memory tasks [5]. However, the variance in memory decline attributed to $A P O E$ is modest. In fact, it has been estimated that in sporadic Alzheimer's disease, a disorder hallmarked by significant memory decline, $50 \%$ of genetic factors remain unidentified [6]. Thus, it is likely that other genetic variants contribute to the memory impairment and decline commonly observed in the aging population.

One possible candidate is the oestrogen $\alpha$-receptor (ESR1) gene. ESR1 is expressed throughout the brain, especially in regions linked to learning and memory, such as the hippocampus and amygdala [7], and oestrogen therapy has been shown to enhance long-term potentiation in these brain regions [8] and improve verbal memory when administered soon after menopause [9]. In addition, research has suggested that genetic variation in ESR1 may impact oestrogen activity by influencing transcription of the ESR 1 gene via altered transcription factor binding [10]. Moreover, several polymorphisms in the ESR1 gene have been implicated in memory impairment and decline and Alzheimer's disease [6, 11]. Of particular interest is a common restriction fragment length polymorphism (PvuII: rs2234693) that has been shown in case-control and longitudinal studies to be associated with cognitive impairment and decline [11]. However, these studies have typically utilized screening tests for global cognitive function [e.g. the modified Mini-Mental State Examination (MMSE)] to determine cognitive impairment and decline, and to date no study has prospectively examined the association between ESR1 and specific tests for episodic memory performance. Thus, more fine-grain impairments and changes in memory performance associated with ESR1 genotypic variation are currently unknown. In an effort to address this gap in the literature, this study examined the influence of the common $P v u I I$ polymorphism on changes in validated neuropsychological tests of verbal and non-verbal episodic memory over a 2-year period among midlife postmenopausal Australian women. Based on previous cohort study findings $[4,6,12]$, we hypothesized that using a battery of specific memory tests rather than the MMSE would assist in identifying and elucidating declines in specific memory domains associated with the PvuII polymorphism. We specifically hypothesized that carriers of the ESR1 PvuII p allele would show greater declines in memory functioning over time compared to non-carriers.

\section{Methods}

\section{Participants}

Participants were selected from the Women's Healthy Ageing Project which commenced in 1991 as the Melbourne Women's Midlife Health Project [13]. Briefly, a longitudinal cohort of 438 Caucasian women within the Melbourne metropolitan area were identified by random telephone dialling in 1991 and re-interviewed over 13 years. Women were eligible for the cohort if they were aged 45-55 years, Australian-born, had menstruated 3 months prior to recruitment and were not taking oestrogen-containing hormone therapy. In 2002 (cohort year 11) and 2004 (year 13), 204 cohort members aged 56-67 were administered a comprehensive neuropsychological battery [14, 15], and in 2002 a venous blood sample was collected for genotyping. At the time of testing, these participants were all postmenopausal and without dementia. The current study examined 80 participants. We excluded 124 participants who were missing ESR1 genotypic data $(n=108)$ or did not have complete neuropsychological measures $(n=16)$. Importantly, our subsample did not significantly differ demographically from the larger neuropsychological sample $(\mathrm{n}=$ 204). However, compared to women in the Melbourne metropolitan population in the same age range, participants were more likely to have completed secondary school (46 vs. $24 \%$ ) and be in paid employment (47 vs. 28\%). All study procedures were approved by the Human Research Ethics Committee at the University of Melbourne.

\section{Testing Procedures}

Detailed testing procedures and descriptions of cognitive tests have been published elsewhere [14, 15]. In brief, participants completed a neuropsychological evaluation in 2002 and again in 2004 that assessed verbal and non-verbal memory, executive functioning, working memory and other cognitive domains. The New Adult Reading Test was included as a measure of baseline intelligence [16]. For the current study, we focused on tests of episodic memory performance, as declines in memory abilities are important predictors of dementia [17], are required for the diagnosis of dementia [18] and are commonly associated with aging [5]. Four memory tests were available, each including measures of immediate and delayed recall and assessing verbal and nonverbal episodic memory. Two supraspan word list learning tasks involved related words (a shortened version of the California Verbal Learning Test II [19]) and unrelated words (adapted from the list learning task from the Consortium to Establish a Registry for Alzheimer's Disease [20]). Logical memory, a variety of verbal episodic memory requiring recall of a short paragraph story, was measured using immediate and delayed trials of the East Boston Memory Test (EBMT) [21]. Visual episodic memory was measured using the Faces subset of the Wechsler Memory Scale III [22].

In addition to the neuropsychological measures, participants' age, education, employment status, chronic illness history, sleeping aid use and family history of dementia were collected at baseline testing. At baseline and 2-year follow-up testing, self-reported current hormone therapy, smoking status, weekly alcohol intake and mood (using the 10-item Center for Epidemiological Studies Depression Scale [23]) were collected. Free oestradiol and testosterone were measured using fasting morning blood samples at the time of baseline testing as described elsewhere [24]. 


\section{Genotyping}

DNA from peripheral blood mononuclear cells were genotyped using a $5^{\prime}$ exonuclease assay for the restriction fragment length polymorphism detected by the enzyme PvuII in intron 1 of the ESR1 gene at the University of Southern California. The $P v u I I$ restriction site results from a $\mathrm{T}$ to $\mathrm{C}$ point mutation (rs2234693) 400 base pairs upstream from exon 2 [12]. The PvuII polymorphism was coded in accordance with previous studies [12] as $\mathrm{P}$ or $\mathrm{p}$, in which $\mathrm{P}$ signifies the absence of the restriction site and $\mathrm{p}$ signifies its presence. In addition, APOE genotyping based on restriction enzyme isotyping was carried out as previously described [25] to identify participants carrying the e4 allele.

\section{Statistical Analysis}

Prior to analysis, ESR1 genotype was dichotomized (PP vs. Pp or $\mathrm{pp}$ ) based on previous findings that suggest that carriers of the $\mathrm{p}$ allele (i.e. presence of restriction site) are at greater risk for cognitive impairment [12]. Proportional, mean and median differences in participant characteristics at baseline and follow-up by ESR1 genotype were examined using Fisher's exact test, Student's t test and the Mann-Whitney (Wilcoxon) test, respectively. In addition, odds ratios and 95\% confidence intervals were calculated when appropriate. Repeated-measures analysis of covariance (ANCOVA) was employed to test for ESR1 genotype by time interaction effects for each of the memory tests, while adjusting for covariates. Effect sizes were calculated using Cohen's $d$ method [26]. To rule out two-way interactions between ESR1 and factors with the potential to affect memory decline ( $A P O E$, oestradiol levels and current use of hormone therapy), interaction terms were created and examined. All analyses were conducted using PASW Statistics 18.0.2 (SPSS Inc.).

\section{Results}

\section{Participant Characteristics}

Among the 80 participants, 19 were PP carriers (24\%), 32 were Pp carriers (40\%) and 29 were pp carriers (36\%). Genotypic frequencies were in Hardy-Weinberg equilibrium $(\mathrm{p}=0.06)$. Table 1 shows the demographic, behavioural and hormonal characteristics of participants at baseline and follow-up (if available) testing for the full sample and by ESR1 genotype (PP vs. Pp/pp). No significant demographic, behavioural or hormonal differences were observed between the two genotype groups at baseline, with the exception of age $(\mathrm{p}=0.05)$. Borderline significance was noted for oestradiol levels $(\mathrm{p}=0.07)$ at baseline. Both age and oestradiol levels were included as covariates in the ANCOVA models. Changes in mood and alcohol consumption from baseline to follow-up were not significantly different between the two genotype groups.

\section{Memory Performance by Genotype}

Performance on all memory tests across both genotype groups improved or remained stable from baseline to follow-up, with the exception of EBMT performance for carriers of the pp or Pp genotype (fig. 1). A nominally significant ESR1 by time interaction $(\mathrm{p}=0.01)$ for the EBMT delayed recall test was observed, adjusting for age and oestradiol levels. Carriers of the $\mathrm{p}$ allele declined significantly $(d=0.62)$ during the 2 -year follow-up period, while PP carriers showed a modest improvement in performance $(d=0.40)$. We did not observe two-way interactions between ESR1 and APOE genotype ( $\mathrm{p}=0.54), E S R 1$ and baseline oestradiol levels $(\mathrm{p}=0.10)$ or ESR 1 and current use of hormone therapy $(\mathrm{p}=0.14)$ for performance change on any of the tests examined.

\section{Discussion}

In a sample of 80 midlife postmenopausal Australian women, we observed a significant albeit modest 2-year decline in performance on EBMT delayed paragraph recall (logical memory; a measure of episodic memory) among participants with the Pp or pp genotype that was not observed among PP carriers. A considerable strength of these findings is that both genotype groups were comparable at baseline with regards to education, employment status, intelligence, family history of dementia, chronic illness, sleep aid usage, testosterone/oestradiol molar ratio levels, depressed mood, smoking status, alcohol consumption and APOE e4 carrier status. Furthermore, both groups were balanced with regard to prospective changes in mood, smoking status and alcohol consumption, all of which have been associated with memory performance, memory decline or both. Although age was 'statistically' different between the two genotype groups, the clinical relevance of the observed 1 -year difference in age is not clear.

Our findings are aligned with previous case-control, cross-sectional and prospective cohort studies that have reported that carriers of the $\mathrm{p}$ allele are at greater risk for cognitive impairment and decline and Alzheimer's disease $[4,6,11,12,27]$, although others have found no relationship [28-31] or have reported that cognitive risk is conferred by the $\mathrm{P}$ allele $[32,33]$. Our results strengthen and expand the cross-sectional findings of Kravitz et al. [4] in particular, who showed that Caucasian women with the PP genotype performed significantly better on the EBMT delayed paragraph recall than their pp counterparts. In fact, to our knowledge we are the first to show that prospective declines in logical memory performance may be dependent on ESR1 PvuII genotype. Three previous prospective studies $[6,12,34]$ examining ESR1 only 
Table 1. Characteristics of participants at baseline and follow-up by ESR1 (PvuII: rs2234693) genotype

\begin{tabular}{|c|c|c|c|c|c|}
\hline & $\begin{array}{l}\text { Full sample } \\
(\mathrm{n}=80)\end{array}$ & $\begin{array}{l}\mathrm{PP} \\
(\mathrm{n}=19)\end{array}$ & $\begin{array}{l}\mathrm{Pp} / \mathrm{pp} \\
(\mathrm{n}=61)\end{array}$ & $\mathrm{p}$ value & OR $(95 \% \mathrm{CI})$ \\
\hline \multicolumn{6}{|l|}{ Baseline variables, 2002} \\
\hline Age, years & $60 \pm 2.5$ & $61 \pm 2.3$ & $60 \pm 2.5$ & 0.05 & n.a. \\
\hline Education, years & $12 \pm 2.2$ & $12 \pm 2.1$ & $12 \pm 2.3$ & 0.65 & n.a. \\
\hline Mood (CESD score) & $7 \pm 3.9$ & $7 \pm 4.5$ & $7 \pm 3.7$ & 0.42 & n.a. \\
\hline Baseline intelligence (NART score) & $36 \pm 6.7$ & $35 \pm 8.7$ & $36 \pm 6.0$ & 0.83 & n.a. \\
\hline Alcoholic drinks/week & $4 \pm 1.8$ & $5 \pm 1.5$ & $4 \pm 1.9$ & 0.73 & n.a. \\
\hline Smoker, $\mathrm{n}$ & $8(10)$ & $1(5)$ & $7(12)$ & 0.38 & $2.3(0.27-20.2)$ \\
\hline Employed, n & $37(47)$ & $8(44)$ & $29(48)$ & 0.52 & $1.1(0.38-3.26)$ \\
\hline$A P O E$ e 4 carrier, $\mathrm{n}$ & $23(29)$ & $7(39)$ & $16(26)$ & 0.27 & $0.6(0.18-1.68)$ \\
\hline Family history of dementia, $\mathrm{n}$ & $25(33)$ & $7(39)$ & $18(32)$ & 0.46 & $1.2(0.41-3.65)$ \\
\hline Current hormone therapy, $\mathrm{n}$ & $8(10)$ & $3(16)$ & $5(8)$ & 0.30 & $0.5(0.11-2.29)$ \\
\hline Allergy history, n & $15(19)$ & $3(16)$ & $12(20)$ & 0.99 & $1.4(0.34-5.45)$ \\
\hline Asthma history, $\mathrm{n}$ & $1(1.5)$ & $0(0)$ & $1(2)$ & 0.99 & $3.3(0.00-99.9)$ \\
\hline Hypertension history, $\mathrm{n}$ & $25(31)$ & $6(32)$ & $19(32)$ & 0.60 & $1.0(0.34-3.13)$ \\
\hline Diabetes history, $\mathrm{n}$ & $2(3)$ & $0(0)$ & $2(4)$ & 0.57 & $1.3(0.06-30.8)$ \\
\hline Sleeping aid use, $\mathrm{n}$ & $4(5)$ & $0(0)$ & $4(7)$ & 0.57 & $2.8(0.14-54.7)$ \\
\hline Oestradiol, pg/ml & $16(12-32)$ & $13(10-16)$ & $16(8-35)$ & 0.07 & n.a. \\
\hline Testosterone, ng/dl & $11(8-16)$ & $10(7-16)$ & $13(8-16)$ & 0.33 & n.a. \\
\hline Testosterone/oestradiol, molar ratio & $12(6-18)$ & $10(8-20)$ & $12(5-17)$ & 0.68 & n.a. \\
\hline \multicolumn{6}{|l|}{ Follow-up variables, 2004} \\
\hline Current hormone therapy, $\mathrm{n}$ & $18(23)$ & $3(16)$ & $15(26)$ & 0.29 & $1.9(0.45-7.29)$ \\
\hline Mood (CESD score) & $7 \pm 4.1$ & $8 \pm 4.7$ & $7 \pm 3.9$ & 0.41 & n.a. \\
\hline Alcoholic drinks/week & $4 \pm 2.0$ & $5 \pm 1.8$ & $4 \pm 2.0$ & 0.14 & n.a. \\
\hline Smoker, $\mathrm{n}$ & $8(10)$ & $1(5)$ & $7(12)$ & 0.38 & $2.3(0.27-20.2)$ \\
\hline \multicolumn{6}{|l|}{ Two-year change variables, 2002-2004 } \\
\hline Mood (CESD score) & $0 \pm 3.4$ & $1 \pm 3.2$ & $0 \pm 3.4$ & 0.47 & n.a. \\
\hline Alcoholic drinks/week & $0 \pm 1.7$ & $0 \pm 1.8$ & $0 \pm 1.7$ & 0.18 & n.a. \\
\hline
\end{tabular}

Values represent means $\pm \mathrm{SD}$, numbers (percentage) or medians (interquartile range), as appropriate. $\mathrm{p}$ values were calculated using Student's t test/Mann-Whitney test or Fisher's exact test. The reference group for odds ratios (OR) and 95\% confidence intervals (CI) is PP. CESD = Center for Epidemiologic Studies Depression Scale; NART = New Adult Reading Test; n.a. = not applicable.

utilized the MMSE to measure declines in cognitive functioning. Two of these studies conducted by the same chief investigator $[6,12]$ reported significantly greater longitudinal (4-8 years) declines in MMSE scores for carriers of the $p$ allele [12] and a marginal association between the $p$ allele and cognitive impairment at baseline [6] in a large cohort of Caucasian women over the age of 65 . The third study [34] found no association between the ESR1 PvuII polymorphism and risk for Alzheimer's disease or allcause dementia but did report a trend $(p=0.10)$ between the number of $\mathrm{p}$ alleles and lower hippocampal volume, a brain region associated with episodic memory [35]. Thus, one would expect that the strongest association would be with episodic memory, consistent with our findings as measured by the EBMT. However, we did not observe a similar 2-year decline on the California Verbal
Learning Test, unrelated word list or memory for faces. This discordant finding among memory tests could be a result of differences in practice effects for these tests. In fact, the EBMT was the only test in the battery that detected declines in performance, suggesting it was more resistant to any potential practice effects in this cohort. Another potential explanation is that performance on the EBMT is more susceptible to an interaction with ESR1 due to the nature of the test. The EBMT paragraph recall, unlike the other memory tests examined, includes emotional elements (e.g. house on fire, rescued children, injuries) that may elicit more involvement of the amygdala, a brain region linked to emotional memory [36]. Although this is speculative and requires further functional examination, ESR1 is more highly expressed in the amygdala than the hippocampus [7] and thus it could be 
Fig. 1. Memory test performance over 2 years by ESR1 (PvuII: rs2234693) genotype. Black lines represent $\mathrm{Pp} / \mathrm{pp}$ genotype $(\mathrm{n}=61)$ and grey lines represent PP genotype $(n=19)$. Nodes represent the mean and bars represent the standard error of the mean. All F tests were adjusted for age and oestradiol level. CVLT $=$ California Verbal Learning Test.
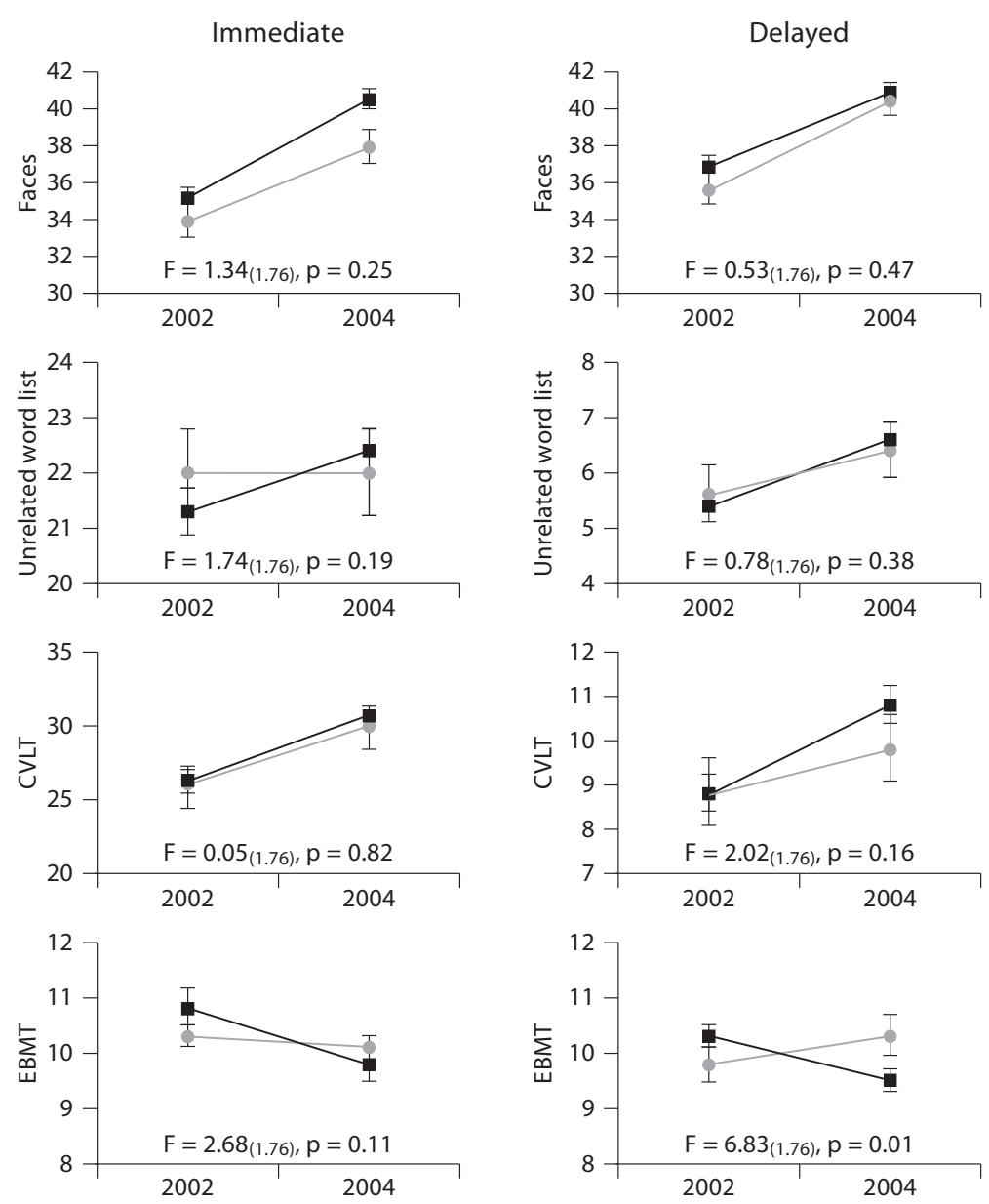

that the observed decline in performance for ESR1 p allele carriers on the EBMT is a result of impaired oestrogenmediated long-term potentiation in the amygdala leading to attenuation of the memory enhancement effect that is normally attributed to emotional elements [37].

Several caveats to the current study should be acknowledged. First and foremost, our sample was small, relatively young and healthy and included only a subset of participants from the larger Melbourne Women's Healthy Ageing Project cohort. Thus, our ability to detect genotypic effects was attenuated and our results should be interpreted with caution. In fact, when applying a conservative Bonferroni correction for multiple testing ( $\alpha$ threshold $=0.006$ ), no significant genotypic effect remained. However, given complementary findings in the literature and reasonable biological plausibility, the ob- served effect of ESR1 PvuII on EBMT performance warrants further examination. Second, although our genotypic groups were generally comparable at baseline and follow-up, hormonal factors that were measured at baseline were not available at follow-up. It is possible that unmeasured changes in the testosterone/oestradiol molar ratio over the 2-year follow-up may have confounded genotypic effects observed in the current study, although there were no genotypic group differences in current use of hormone therapy at baseline or follow-up. Third, our battery of four memory tests, a considerable strength compared to previous research, included only a subset of memory tests that are commonly used. Additional memory tests could be examined to determine if the effect observed in this study is specific to EBMT performance or if it is generalizable to other tests of logical memory. Fi- 
nally, the functional relevance of the PvuII polymorphism has yet to be fully elucidated, and previous prospective studies examining the $P v u I I$ polymorphism have also examined the Xbal and/or other variants in the $5^{\prime}$ end of the ESR1 gene. In these studies, the Xbal polymorphism was associated with the development of cognitive impairment and cognitive decline utilizing the MMSE $[6,12]$. Thus, future prospective research is needed to determine if the Xbal variant as well as other variants in the ESR1 gene are associated with more specific measures of memory performance (e.g. EBMT).

In summary, we observed significant albeit modest performance declines on the EBMT, an episodic memory task, among midlife postmenopausal Australian women carrying the p allele of the ESR1 PvuII polymorphism. These results provide preliminary data for larger pro- spective trials that will be able to determine if the $\mathrm{p}$ allele of the ESR1 PvuII polymorphism is a potential biomarker of memory decline among aging women.

\section{Acknowledgments}

We are indebted to the women in the project, who generously donated their time to participate in this research study.

This research was partly supported by the Brain Foundation, Alzheimer's Association of Australia, the Scobie and Claire McKinnon Foundation, the Collier Trust Fund, the Ramaciotti Foundation, Bayer Pharmaceuticals, the J.O. \& J.R. Wicking Trust and the National Health and Medical Research Council (C.S.), the University of Melbourne and the Alzheimer's Association IIRG01-2684 (V.W.H.). The efforts of C.A.B. were supported by a John McKenzie Post-Doctoral Research Fellowship.

\section{References}

1 World Population Ageing (Report No. ESA/P/WP/212). New York, United Nations Department of Economic and Social Affairs, 2009.

2 Linn RT, Wolf PA, Bachman DL, Knoefel JE, Cobb JL, Belanger AJ, et al: The 'preclinical phase' of probable Alzheimer's disease. A 13year prospective study of the Framingham cohort. Arch Neurol 1995;52:485-490.

-3 Meyer PM, Powell LH, Wilson RS, EversonRose SA, Kravitz HM, Luborsky JL, et al: A population-based longitudinal study of cognitive functioning in the menopausal transition. Neurology 2003;61:801-806.

-4 Kravitz HM, Meyer PM, Seeman TE, Green dale GA, Sowers MR: Cognitive functioning and sex steroid hormone gene polymorphisms in women at midlife. Am J Med 2006; 119(9 suppl 1):S94-S102.

$\checkmark 5$ Daviglus ML, Bell CC, Berrettini W, Bowen PE, Connolly ES Jr, Cox NJ, et al: National Institutes of Health State-of-the-Science Conference statement: preventing Alzheimer disease and cognitive decline. Ann Intern Med 2010;153:176-181.

-6 Yaffe K, Lindquist K, Sen S, Cauley J, Ferrell $\mathrm{R}$, Penninx B, et al: Estrogen receptor genotype and risk of cognitive impairment in elders: findings from the Health $\mathrm{ABC}$ study. Neurobiol Aging 2009;30:607-614.

7 Osterlund MK, Keller E, Hurd YL: The human forebrain has discrete estrogen receptor alpha messenger RNA expression: high levels in the amygdaloid complex. Neuroscience 2000;95:333-342.

8 McEwen BS: Clinical review 108: the molecular and neuroanatomical basis for estrogen effects in the central nervous system. J Clin Endocrinol Metab 1999;84:1790-1797.
-9 Sherwin BB: Estrogen and cognitive functioning in women: lessons we have learned. Behav Neurosci 2012;126:123-127.

10 Schuit SC, de Jong FH, Stolk L, Koek WN, van Meurs JB, Schoofs MW, et al: Estrogen receptor alpha gene polymorphisms are associated with estradiol levels in postmenopausal women. Eur J Endocrinol 2005;153: 327-334

-11 Sundermann EE, Maki PM, Bishop JR: A review of estrogen receptor alpha gene (ESR1) polymorphisms, mood, and cognition. Menopause 2010;17:874-886.

12 Yaffe K, Lui LY, Grady D, Stone K, Morin P. Estrogen receptor 1 polymorphisms and risk of cognitive impairment in older women. Biol Psychiatry 2002;51:677-682.

13 Dennerstein L, Smith AM, Morse C, Burger H, Green A, Hopper J, et al: Menopausal symptoms in Australian women. Med J Aust 1993;159:232-236.

14 Clark MS, Dennerstein L, Elkadi S, Guthrie JR, Bowden SC, Henderson VW: Normative verbal and non-verbal memory test scores for Australian women aged 56-67. Aust NZ J Psychiatry 2004;38:532-540.

15 Clark MS, Dennerstein L, Elkadi S, Guthrie JR, Bowden SC, Henderson VW: Normative data for tasks of executive function and working memory for Australian-born women aged 56-67. Aust Psychol 2004;39:244-250.

16 Nelson HE, O'Connell A: Dementia: the estimation of premorbid intelligence levels using the New Adult Reading Test. Cortex 1978;14:234-244.

17 Salmon DP, Lange KL: Cognitive screening and neuropsychological assessment in early Alzheimer's disease. Clin Geriatr Med 2001; 17:229-254.
18 American Psychiatric Association: Diagnostic Criteria from DSM-IV. Washington, American Psychiatric Association, 1994.

19 Delis D, Kramer J, Kaplan E: CVLT-II Adult Version. San Antonio, Harcourt-Brace, 2000.

20 Collie A, Shafiq-Antonacci R, Maruff P, Tyler P, Currie J: Norms and the effects of demographic variables on a neuropsychological battery for use in healthy ageing Australian populations. Aust NZ J Psychiatry 1999; 33:568-575.

-21 Scherr PA, Albert MS, Funkenstein HH, Cook NR, Hennekens CH, Branch LG, et al: Correlates of cognitive function in an elderly community population. Am J Epidemiol 1988;128:1084-1101

22 Wechsler D: Wechsler Memory Scale - Revised Manual. San Antonio, Tex., The Psychological Corporation, 1987.

-23 Andresen EM, Malmgren JA, Carter WB, Patrick DL: Screening for depression in well older adults: evaluation of a short form of the CES-D (Center for Epidemiologic Studies Depression Scale). Am J Prev Med 1994;10: 77-84.

24 Ryan J, Stanczyk FZ, Dennerstein L, Mack WJ, Clark MS, Szoeke C, et al: Hormone levels and cognitive function in postmenopausal midlife women. Neurobiol Aging 2012;33: 1138-1147.

25 Hixson JE, Vernier DT: Restriction isotyping of human apolipoprotein E by gene amplification and cleavage with HhaI. J Lipid Res 1990;31:545-548.

26 Cohen J: Statistical Power Analysis for the Behavioral Sciences. Hillsdale, Erlbaum, 1988

Bousman/Szoeke/Chen/Dennerstein/ Henderson/Everall 
-27 Mattila KM, Axelman K, Rinne JO, Blomberg M, Lehtimaki T, Laippala $\mathrm{P}$, et al: Interaction between estrogen receptor 1 and the epsilon4 allele of apolipoprotein $\mathrm{E}$ increases the risk of familial Alzheimer's disease in women. Neurosci Lett 2000;282:45-48.

-28 Maruyama H, Toji H, Harrington CR, Sasaki K, Izumi Y, Ohnuma T, et al: Lack of an association of estrogen receptor alpha gene polymorphisms and transcriptional activity with Alzheimer disease. Arch Neurol 2000; 57:236-240.

-29 Monastero R, Cefalu AB, Camarda C, Noto D, Camarda LK, Caldarella R, et al: Association of estrogen receptor alpha gene with Alzheimer's disease: a case-control study. J Alzheimers Dis 2006;9:273-278.
30 Olsen L, Rasmussen HB, Hansen T, Bagger YZ, Tanko LB, Qin G, et al: Estrogen receptor alpha and risk for cognitive impairment in postmenopausal women. Psychiatr Genet 2006;16:85-88.

-31 Usui C, Shibata N, Ohnuma T, Higashi S, Ohkubo T, Ueki A, et al: No genetic association between the myeloperoxidase gene -463 polymorphism and estrogen receptor-alpha gene polymorphisms and Japanese sporadic Alzheimer's disease. Dement Geriatr Cogn Disord 2006;21:296-299.

32 Isoe-Wada K, Maeda M, Yong J, Adachi Y, Harada H, Urakami K, et al: Positive association between an estrogen receptor gene polymorphism and Parkinson's disease with dementia. Eur J Neurol 1999;6:431-435.

-33 Ji Y, Urakami K, Wada-Isoe K, Adachi Y, Nakashima K: Estrogen receptor gene polymorphisms in patients with Alzheimer's disease, vascular dementia and alcohol-associated dementia. Dement Geriatr Cogn Disord 2000;11:119-122.
34 den Heijer T, Schuit SC, Pols HA, van Meurs JB, Hofman A, Koudstaal PJ, et al: Variations in estrogen receptor alpha gene and risk of dementia, and brain volumes on MRI. Mol Psychiatry 2004;9:1129-1135.

35 Maguire EA: Neuroimaging, memory and the human hippocampus. Rev Neurol (Paris) 2001;157:791-784

36 Cahill L, Babinsky R, Markowitsch HJ, McGaugh JL: The amygdala and emotional memory. Nature 1995;377:295-296.

-37 Adolphs R, Cahill L, Schul R, Babinsky R: Impaired declarative memory for emotional material following bilateral amygdala damage in humans. Learn Mem 1997;4:291-300. 